\title{
Determination of oestrogen hormones in raw and treated water samples by reverse phase ultra-fast liquid chromatography mass spectrometry - a case study in Johannesburg South, South Africa
}

\author{
SB Mnguni ${ }^{1 *}$, C Schoeman', SS Marais ${ }^{1}$, E Cukrowska² and L Chimuka ${ }^{2}$ \\ 'Rand Water Analytical Services, Barrage Road, Vereeniging 1939, South Africa \\ ${ }^{2}$ School of Chemistry, University of the Witwatersrand, P/Bag 3, WITS 2050, Johannesburg, South Africa
}

\begin{abstract}
Hormones in water samples have been classified as 'emerging pollutants' and may pose a potential risk for humans. Hormones can be found in both surface and ground water at low concentrations. These compounds enter water streams through wastewater treatment plants (WWTP) and may elicit endocrine disruption to organisms. As a result of the low concentrations, a suitable analytical methodology is essential for their determination. In the past, residues of oestrogens in aqueous and solid environmental samples have commonly been analysed by gas chromatography (GC) equipped with mass spectrometry (MS). However, the necessary derivatisation steps are not only time consuming and laborious but also tedious. The first part of this case study was to develop a method to determine trace concentrations of the estrone (E1), 17 $\alpha$-estradiol (E2a), 17- $\beta$-estradiol $(E 2 \beta)$ and 17- $\alpha$-ethinylestradiol (EE2) hormones using reverse phase ultra-fast liquid chromatography mass spectrometry (RP-UFLC). Using the developed method, the second part of the case study was to determine the concentrations of the hormones in raw and treated potable water samples from the Vaal River catchment area in the south of Johannesburg, South Africa. Analytes were extracted by solid phase extraction ( $\mathrm{SPE} \mathrm{C}_{18}$ sorbent) cartridges and subsequently injected into ultra-fast liquid chromatography with the reverse phase column coupled to mass spectrometry (UFLC-MS) for analyte determinations. The limits of quantification were in the range of 0.24 to $0.32 \mathrm{ng} \cdot \mathrm{L}^{-1}$ for the analytes. Accuracy was $95.6,93.8,97.6$ and $100.9 \%$ for EE2, $\mathrm{E} 2 \alpha, \mathrm{E} 2 \beta$ and E1, respectively. In raw water samples taken during the rainy wet season, estrone was detected at concentrations of 0.90 and $4.43 \mathrm{ng} \cdot \mathrm{L}^{-1}$. However, treated potable water samples did not contain detectable levels of hormones. This is potentially due to the ability of a water treatment process to remove endocrine disruptors during water purification.
\end{abstract}

Keywords: hormones, endocrine disrupting compounds, oestrogens, Vaal River, RP-UFLC

\section{INTRODUCTION}

The occurrence of human pharmaceuticals and endocrine disrupting compounds (EDCs) in waste waters and in surface waters has been demonstrated and widely evaluated over the past decade (Carballa et al., 2004; Richardson, 2009; HuertaFontela et al., 2011). These compounds, together with their metabolites, enter the environment primarily through domestic use, via sewage treatment plants. If these compounds are not eliminated by wastewater treatment plants, they can then be discharged to rivers and lakes which are used as sources for drinking water production. Therefore, the presence of such organic contaminants may have a negative impact on the quality of drinking water together with unknown toxicological effects (Huerta-Fontela et al., 2011).

Huerta-Fontela et al. (2011) further reported that a significant feminization of aquatic life could be observed at a concentration of approximately $1 \mathrm{ng} \cdot \mathrm{L}^{-1}$, reflecting the strong endocrine disrupting potential of these compounds. To date, several EDCs have been found in European and United States of America (USA) tap waters, at concentrations ranging from ng. $\mathrm{L}^{-1}$ to low $\mathrm{mg} \cdot \mathrm{L}^{-1}$ (Huerta-Fontela et al., 2011).

Natural oestrogens, consisting of estrone (E1), 17- $\alpha$ - estradiol and $17-\beta$-estradiol, are steroid hormones with the general skeleton as shown in Fig. 1, generated from cholesterol via

To whom all correspondence should be addressed.

욜 +2716430-8408

e-mail: smnguni@randwater.co.za

Received 7 July 2015, accepted in revised form 12 January 2018. testosterone and androstenedione in ovaries, brain, and body fat deposits (Nguyen, 2011; Tedmon et al., 2013). EE2 (19-nor-17apregna-1, 3, 5(10)-trien-20-yne-3, 17-diol) is a derivative from the natural hormone, estradiol (E2) (Aris et al., 2014). EE2 is used in almost all modern formulations of combined oral contraceptive pills and is one of the most commonly used medications. It is worth noting that EE2 is sparingly soluble in ethanol (1 part in 6 parts of ethanol), but has relatively low solubility in water $\left(4.8 \mathrm{mg} \cdot \mathrm{L}^{-1}\right.$ at $20^{\circ} \mathrm{C}$ ) compared to natural oestrogenic steroid (Lewis and Archer, 1979).

Vulliet et al. (2011) reported estrone to be detected in $20 \%$ (out of 21 samples) of waters in Barcelona, Spain, at concentrations generally in the region of 0.1 to $1 \mathrm{ng} \cdot \mathrm{L}^{-1}$. Only 3 out of 21 samples exceeded $1 \mathrm{ng} \cdot \mathrm{L}^{-1}$ of estrone. The presence of estrone is common when detecting hormones in samples because it is the most abundant natural oestrogen excreted by cycling women; it is also the by-product of biodegradation of estradiol (Huerta-Fontela et al., 2010). Another study has been reported for these compounds in Mess River during the floodwater season in Luxembourg (Pailler et al., 2009). The concentrations obtained were ibuprofen (9-2382 ng.L.-1), E1 (4-27 ng. $\left.\mathrm{L}^{-1}\right)$ and diclofenac (3-20 ng. $\mathrm{L}^{-1}$ ) (Pailler et al., 2009). The river concentration of E2 was relatively high ( $\left.35 \mathrm{ng} \cdot \mathrm{L}^{-1}\right)$, especially when taking into account its presumed endocrine disrupting effect on animals at this level (Pailler et al., 2009).

A suitable analytical methodology is essential to determine low or trace concentrations of EDCs. In the past, residues of oestrogens in aqueous and solid environmental samples have been commonly analysed by gas chromatography (GC) equipped with mass spectrometry (MS); however, the necessary derivatisation steps are not only time consuming and laborious 


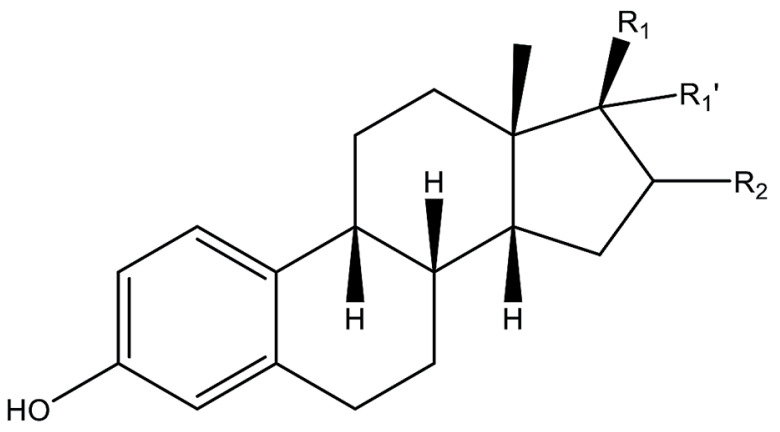

Estrone (E1)

$$
\mathrm{R}_{1}=\mathrm{O} ; \mathrm{R}_{2}: \mathrm{H}
$$

Estradiol (E2)

$\mathrm{R}_{1}: \mathrm{OH}: \mathrm{R}_{1}^{\prime}: \mathrm{H} \mathrm{R}_{2}: \mathrm{H}$

Ethinyl Estradiol (EE2)

$\mathrm{R}: \mathrm{OH} ; \mathrm{R}_{1}: \mathrm{CH} \equiv \mathrm{CH} ; \mathrm{R}_{2}: \mathrm{H}$

Figure 1

Structure of oestrogenic hormones (from Lewis and Archer, 1979)

but also tedious (Huerta-Fontela et al., 2010; Huerta-Fontela et al., 2011).

The UFLC-MS is able to simultaneously analyse multiple target analytes within one sample run. Over the past 10 years, commonly-used LC-MS has become a reliable standard technique in clinical application fields like therapeutic drug monitoring (TDM), new-born screening, and toxicological diagnostics (Vogeser et al., 2016; Wolff et al., 1999). Therefore, UFLC-MS has the potential to become a strong competitor for widely-used immunoassays for steroid analysis, especially when more than one steroid hormone has to be analysed with high selectivity, sensitivity, precision and accuracy (Koal et al., 2012).

The main advantage of liquid chromatographic (LC) techniques in the analysis of environmental samples for oestrogens is that sulphuric and glucuronic metabolites can be determined without the need for derivatisation, as is the case for GC systems. Most common derivatisation in LC is intended to enhance detectability by ultraviolet absorption, fluorescence, or electrochemistry (Chan et al., 2011; De Jager et al., 2011). Use of triethylamine or ammonium-acetate for buffering the mobile phase is widely documented. A pH-adjustment of the eluent sometimes reacts with the silica in silica-based columns unless the post-column addition of ammonia or trimethylamine is used (Ingerslev et al.,2003).

However, UFLC-MS needs comprehensive standardisation to become a successfully established technology in routine laboratories for steroid hormone analysis. Standardisation is needed to minimise analytical intra and inter-laboratory variability (imprecision and inaccuracy) and to improve the quality of the quantitative results (Huerta-Fontela et al., 2011; Izumi et al., 2009).

Herein we developed and validated a new method for simultaneous determination of hormones in environmental water samples using a highly sophisticated UFLC coupled to triple quadrapole mass spectrometry (MS-MS). The developed method was applied for the detection of hormones in raw and treated potable water samples within the Vaal River catchment area situated in the south of Johannesburg, South Africa. Little is known of the presence of pharmaceuticals and hormones in raw waters that are treated for drinking water, especially in South Africa. The need for further studies on detection of these emerging pollutants should be of utmost importance to ensure the health and safety of consumers. The lack of systematic monitoring programmes in South Africa and fluctuating concentrations of hormones with inadequate analytical methods of detection may possibly exacerbate the situation.

\section{MATERIALS AND METHODS}

\section{Sample collection and study area}

Samples were collected in $1000 \mathrm{~mL}$ amber glass bottles and transported to the laboratory. Samples were extracted immediately to avoid biological degradation. A total number of 28 samples of raw and treated water samples, from 14 sampling points, were collected in December 2013 and July 2014 from the Vaal River catchment area for hormone analysis. The Vaal River catchment area is situated in the south of Johannesburg, in Gauteng Province, South Africa.

The samples were collected at 14 sampling points in the south of Johannesburg drinking water supply area, from two source-water catchment areas. Surface water samples collected from the catchment areas were from Sampling Point A (collected on the Gladdedrif Bridge from the Vaal River in Villiers) and Sampling Point B (collected from the Wilge River in Frankfort, Free State). The raw water samples, C, D and E, were collected from the intake of the three water treatment plants (WTPs) in the south of Johannesburg. Final treated water samples were collected at Sampling Points F, G, H and I. Other treated water samples ( $\mathrm{J}$ and $\mathrm{K}$ ) were also collected at a sampling point $5 \mathrm{~km}$ after chlorination by the two WTPs (C and D). Additional samples were also collected at the booster stations before and after chloramination at Sampling Points $\mathrm{L}$ and $\mathrm{M}$, respectively.

\section{Chemicals and reagents}

High-purity standards for estrone (E1, > 99.0\%), $17 \beta$-estradiol (E2, > 99.0\%), 17 $\alpha$-estradiol (E2, > 99.0\%) and 17a-ethinylestradiol (EE2, > 99.0\%) were purchased from Sigma Aldrich (St. Louis, USA). Methanol (99.9\%), GC and HPLC grade was purchased from Merck (Johannesburg, South Africa). HPLC grade acetonitrile (99.9\%) was purchased from Burdick \& Jackson (Johannesburg, South Africa); liquid ammonia $\left(\mathrm{NH}_{3}\right)$ for $\mathrm{pH}$ adjustment was purchased from Sigma Aldrich (St. Louis, USA). Deionised water for blank determination was purified in a Milli-Q system (Millipore) supplied by Merck South Africa.

\section{Preparation of stock solution and calibration}

Standard stock solutions were prepared by dissolving $10 \mathrm{mg}$ of each hormone compound (E1, E2 isomers and EE2) into a $10 \mathrm{~mL}$ volumetric flask using a $50 \%$ methanol solution. A mixed standard containing a concentration of $0.01 \mu \mathrm{L}^{-1}$ was prepared from the stock solutions following further dilutions. A multi calibration solution containing target compounds at concentrations of $0.2,0.4,0.6,0.8$ and $1.0 \mathrm{ng} \cdot \mathrm{L}^{-1}$ was prepared in $1 \mathrm{~L}$ of deionised water and extracted using a laboratorydeveloped SPE method.

SPE (Agela PEP $\left(\mathrm{C}_{18}\right), 200 \mathrm{mg} 6 \mathrm{~mL}$ ) cartridges were conditioned with 3 aliquots of $10 \mathrm{~mL}$ methanol in an assembled SPE manifold. An amount of $10 \mathrm{~mL}$ of reagent water was then added to each cartridge followed by percolation of $1 \mathrm{~L}$ samples at a flow rate of $10 \mathrm{~mL} \cdot \mathrm{min}^{-1}$ under small vacuum. 
Cartridges containing extracted analytes were further dried under full vacuum for about 10 to $15 \mathrm{~min}$, followed by the slow elution of analyte with methanol into collection tubes. A total volume of $7.5 \mathrm{~mL}$ of methanol was used to elute analytes from the SPE cartridge.

The extract was then concentrated to dryness with nitrogen before adjusting to a $250 \mu \mathrm{L}$ volume with a $50 \%$ methanol solution. An aliquot was ready to be injected into a UFLC interfaced to a MS. These conditions were standard for all analytes of interest in this study. Analytical samples and spiked samples were extracted in the same way using SPE before final analysis.

\section{Reverse phase chromatography conditions}

The separation was performed using Shimadzu ultra-fast liquid chromatograph (LC-20AB) connected to auto-sampler (SIL20AC) by communication module (CBM 20A). The temperature of the column oven (CTO-10AS) was kept constant at $40^{\circ} \mathrm{C}$.

A volume of $100 \mu \mathrm{L}$ of each sample was introduced into the UFLC and separated on a Phenomenex Kinetex $\mathrm{C}_{18}$ Sorbent $(100 \times 4.6 \mathrm{~mm} ; 2.6 \mu \mathrm{m})$ column (including $\mathrm{C}_{18}$ guard column with $2.1 \mathrm{~mm} \mathrm{ID)}$ at $40^{\circ} \mathrm{C}$. The gradient elution between acetonitrile (containing 5\% water) and water (containing 5\% acetonitrile) was performed at $0.35 \mathrm{~mL} \cdot \mathrm{min}^{-1}$. The gradient elution started with $5 \%$ acetonitrile and increased to $85 \%$ over $9 \mathrm{~min}$ followed by further $3 \mathrm{~min}$ at $85 \%$ acetonitrile.

\section{Mass spectrometry conditions}

An AB Sciex 3200 Q Trap MS-MS system was used. Each $1 \mathrm{mg} \cdot \mathrm{L}^{-1}$ pure hormone standard at a $\mathrm{pH}$ of 10.2 was infused into the mass spectrometry to optimise fragmentation parameters of ions. During the infusion of pure hormone standards, negative and positive modes were investigated; the negative mode produced optimum conditions and as a result it produced intense signals.

The negative ionisation was found to be better compared to the positive ionisation. The mass spectrometry was optimised in negative $\left(\mathrm{M}+\mathrm{H}^{-}\right)$multiple reaction monitoring modes (MRM); the product ions that yielded high sensitivity were used for quantitative analysis.

The optimisation of cone voltage enhanced the sensitivity of parent ions as well as its signal for all analytes. The corresponding declustering potentials (DP), collision energies (CE) and exit potentials (EP) were $-70,-2.5,-70$, respectively, for estradiol isomers, whilst -60 (DP), -4 (CE) and -60 (EP) were recorded for EE2. Corresponding DP, CE and EP for E1 were $-40,-10$ and -40 , respectively. The optimised collision energy values differ from analyte to analyte because MRM ions were investigated independently.

The identification of analyte peaks was further confirmed by using retention times $\left(R_{\mathrm{t}} s\right)$ comparison with standards.

\section{Optimisation of the separation}

Physical properties such as $p K_{\mathrm{a}}$ and $\log K_{\mathrm{ow}}$ are taken into account in order to achieve better extraction efficiencies, since they determine the prevalence of the ionic and neutral forms of compounds as a function of $\mathrm{pH}$ (Huerta-Fontela et al., 2011).

During the method development phase, the mixture of hormones was subjected to UFLC-MS and initially only 3 peaks were observed due to co-elution estradiol isomers. The co-elution of isomers $17 \beta$-estradiol $(\beta$-E2) and $17 \alpha$-estradiol ( $\alpha$-E2) was due to similar chemical properties. Analytical gradient conditions were further optimised to achieve the separation of 2 peaks at 4.72 and $4.91 \mathrm{~min}$. The co-elution of E1 and EE2 at 5.17 min was not considered a problem since their fragmentation ions are different (LaFleur et al., 2011).

\section{Qualitative and quantitative analysis}

Aliquots of hormones were injected into a UFLC interfaced to an MS. Analytes were identified by comparing the mass spectra and retention times to reference spectra for calibration standards acquired under identical UFLC-MS conditions. The concentration of each analyte was determined using the external standardisation technique. Post-column introduction of $0.4 \% \mathrm{NH}_{3}$ at a flow rate of $0.05 \mathrm{~mL} \cdot \mathrm{min}^{-1}$ was performed using a pump system to improve the ionisation process (Carabias-Martínez et al., 2004).

The four compounds identified were chosen as target analytes for this study due to the availability of standards. Estrone, estradiol and ethinylestradiol studied here belong to the same class of oestrogens.

\section{Quality control}

The calibration curves, consisting of 5 points with a range of 0.2 to $1.0 \mathrm{ng} \cdot \mathrm{L}^{-1}$, were used for quality assurance. Calibration standards were prepared daily prior to analysis. All analytical samples and spiked samples were analysed in this analytical range. Any samples above this range were diluted further accordingly. Extraction of samples was done in replicates and accuracy of the method was determined by extraction of spiked samples with known concentration at concentration levels near to expected real samples.

In order to test for inter-day variation of the extraction and analysis of the developed method, a spiked sample of $0.50 \mathrm{ng} \cdot \mathrm{L}^{-1}$ was analysed over the period of 3 non-consecutive days. Limit of detection (LOD) and limit of quantification (LOQ) were derived from the linear calibration equation (Gustavo González et al., 2007). LOD was expressed in response units and was taken as 3 times the signal-to-noise ratio. The LOQ was estimated to be 10 times the signal-tonoise ratio.

\section{RESULTS AND DISCUSSION}

\section{Quality control results}

The overview of the physical and chemical properties of the compounds and some quality control parameters are presented in Table 1. The calibration curves, consisting of 5 points, were linear in the region of 0.2 to $1.0 \mathrm{ng} \cdot \mathrm{L}^{-1}$. Coefficients of determination $\left(r^{2}\right)$ of more than 0.99 were achieved, indicating a good linear dynamic range from 0 to $1.0 \mathrm{ng} \cdot \mathrm{L}^{-1}$ for all of the

TABLE 1

\begin{tabular}{|c|c|c|c|c|}
\hline \multicolumn{5}{|c|}{$\begin{array}{l}\text { TABLE } 1 \\
\text { Physico-chemical properties and parameters of hormones }\end{array}$} \\
\hline Analyte & ${ }^{*} p K_{\mathrm{a}}$ & ${ }^{*} \log K_{\mathrm{ow}}$ & $r^{2}$ & $\begin{array}{c}\text { LOD (LOQ) } \\
\left.\text { (ng } L^{-1}\right)\end{array}$ \\
\hline E1 & 10.7 & 3.7 & 0.998 & $0.07(0.24)$ \\
\hline $\mathrm{E} 2(\alpha)$ & 10.7 & 4.1 & 0.997 & $0.09(0.30)$ \\
\hline $\mathrm{E} 2(\beta)$ & 10.7 & 4.1 & 0.996 & $0.10(0.32)$ \\
\hline EE2 & 10.2 & 4.5 & 0.998 & $0.07(0.24)$ \\
\hline
\end{tabular}

${ }^{\star}$ Hormone properties obtained from Lewis and Archer (1979) 
analytes. The LOD and LOQs for the method were in the range of 0.07 to $0.32 \mathrm{ng} \cdot \mathrm{L}^{-1}$, respectively.

The results of the accuracy test and inter-day comparison are shown in Table 2. Table 2 shows the method performance parameters obtained from the statistical data evaluation; the percentage RSDs ranged from 9.3 to $11.4 \%$, indicating good method precision given the low detection limits required for these analytes. The accuracy of the method was in the region of 93.8 to $100.9 \%$, indicating good performance achieved by the UFLC-MS-MS.

The average precision for all compounds fell within 15\%; this value is acceptable given the ultra-trace nature of these analytes and the complexity of the method. The accuracy was within $\pm 10 \%$ semi-range for most hormones, which is also considered to be acceptable.

The recovery of spiked samples was not determined since calibration standards and analytical samples were extracted in a similar manner. Analysis was performed under similar SPE and optimised instrumental conditions. The uncertainty of measurements was determined using the ISO Guide to the Expression of Uncertainty in Measurement (Ramsey et al., 2007), and ranged between \pm 0.14 and $\pm 0.15 \mathrm{ng} \cdot \mathrm{L}^{-1}$.

\section{Concentration of hormones in water samples}

The study was conducted between December 2013 and June 2014, with samples taken in summer (wet season) as well as winter (dry season); a total combined number of 28 samples were taken for hormone analysis in both seasons. The results for the wet and dry seasons for raw water samples are presented in Table 3.

Figures 2 and 3 show chromatograms where estrone was detected in the raw water samples during the wet season for Sample D and Sample E, at concentrations of 0.90 and 4.43 ng. $\mathrm{L}^{-1}$, respectively. It is important to note that estrone was only detected during the rainy season in this study (Table 3). Oestrogens (estradiol, estrone, and estriol) are female hormones responsible for the development and maintenance of reproductive tissues and secondary sex characteristics in females (Amin et al., 2006; Martini et al., 2015). Estrone is also the main metabolite of $17 \beta$-estradiol (a natural oestrogen) and reaches the environment via the sewer system or animal excretion (ESWE Institute for Water Research and Water Technology, 2003). All 8 treated water samples in both seasons did not contain detectable levels of hormones; this might be due to the ability of a water treatment plant to remove the compounds during the water purification process. Carballa et al. (2004) reported that these compounds are only partially eliminated during conventional (coagulation, sand filtration) water treatment processes. The study reveals that in South Africa the occurrence of hormones (estrone in particular) in raw water is variable, depending on the particular season; the absence of hormones in drinking water reveals that current levels of hormones are potentially removed during conventional water treatment processes. The detection of estrone in water bodies did not come as a surprise because it is also the main metabolite of $17 \beta$-estradiol (a natural oestrogen) (ESWE Institute for Water Research and Water Technology, 2003).

To the best of our knowledge, this is the first time that the selected oestrogens have been investigated in the Vaal River catchment's raw and treated waters using HPLC-MS-MS. This is important for the Gauteng Province which is the most densely populated province.

\section{Comparison with other studies}

Table 4 shows the summarised scope of the detection of hormones in South Africa in comparison with other studies. In this study, estrone was detected in the range of 0.90 to $4.43 \mathrm{ng} \cdot \mathrm{L}^{-1}$ in raw water samples, which is similar to results of

\begin{tabular}{|l|c|c|c|c|c|}
\hline \multicolumn{7}{|c|}{ TABLE 2 } \\
\hline Analyte & $\begin{array}{c}\text { Precision } \\
(\% \mathrm{RSD})\end{array}$ & $\begin{array}{c}\text { Spiked } \\
\text { concentration } \\
\left(\mathbf{n g} \cdot \mathrm{L}^{-1}\right)\end{array}$ & $\begin{array}{c}\text { Obtained } \\
\text { concentration, } \\
(\boldsymbol{n}=\mathbf{8})\left(\mathbf{n g} \cdot \mathrm{L}^{-1}\right)\end{array}$ & $\begin{array}{c}\text { Accuracy } \\
(\%)\end{array}$ & $\begin{array}{c}\text { Uncertainty } \\
+/-\left(\mathbf{n g} \cdot \mathbf{L}^{-1}\right)\end{array}$ \\
\hline E1 & 9.3 & 0.500 & 0.504 & 100.9 & 0.15 \\
\hline E2 $(\alpha)$ & 9.6 & 0.500 & 0.469 & 93.8 & 0.14 \\
\hline E2( $\beta)$ & 11.4 & 0.500 & 0.488 & 97.6 & 0.15 \\
\hline EE2 & 10.7 & 0.500 & 0.478 & 95.6 & 0.14 \\
\hline
\end{tabular}

\begin{tabular}{|c|c|c|c|c|c|}
\hline \multicolumn{6}{|c|}{$\begin{array}{l}\text { TABLE } 3 \\
\text { Results of the raw water samples where the hormones of interest were detected }\end{array}$} \\
\hline \multirow{3}{*}{ Parameter } & \multirow{3}{*}{ Unit of measure } & \multicolumn{4}{|c|}{ Raw water samples } \\
\hline & & \multicolumn{2}{|c|}{$\begin{array}{l}\text { Sample D } \\
\text { (raw water) }\end{array}$} & \multicolumn{2}{|c|}{$\begin{array}{l}\text { Sample E } \\
\text { (raw water) }\end{array}$} \\
\hline & & Wet season & Dry season & Wet season & Dry season \\
\hline E1(269.087/144.900 Da) & $\mathrm{ng} \cdot \mathrm{L}^{-1}$ & 0.90 & nd & 4.43 & nd \\
\hline E2( $\alpha)(271.063 / 144.800 \mathrm{Da})$ & $\mathrm{ng} \cdot \mathrm{L}^{-1}$ & nd & nd & nd & nd \\
\hline $\mathrm{E} 2(\beta)(271.063 / 144.801 \mathrm{Da})$ & $\mathrm{ng} \cdot \mathrm{L}^{-1}$ & nd & nd & nd & nd \\
\hline EE2 $(295.064 / 144.900 \mathrm{Da})$ & $\mathrm{ng} \cdot \mathrm{L}^{-1}$ & nd & nd & nd & nd \\
\hline
\end{tabular}

nd-analytes not detected. 


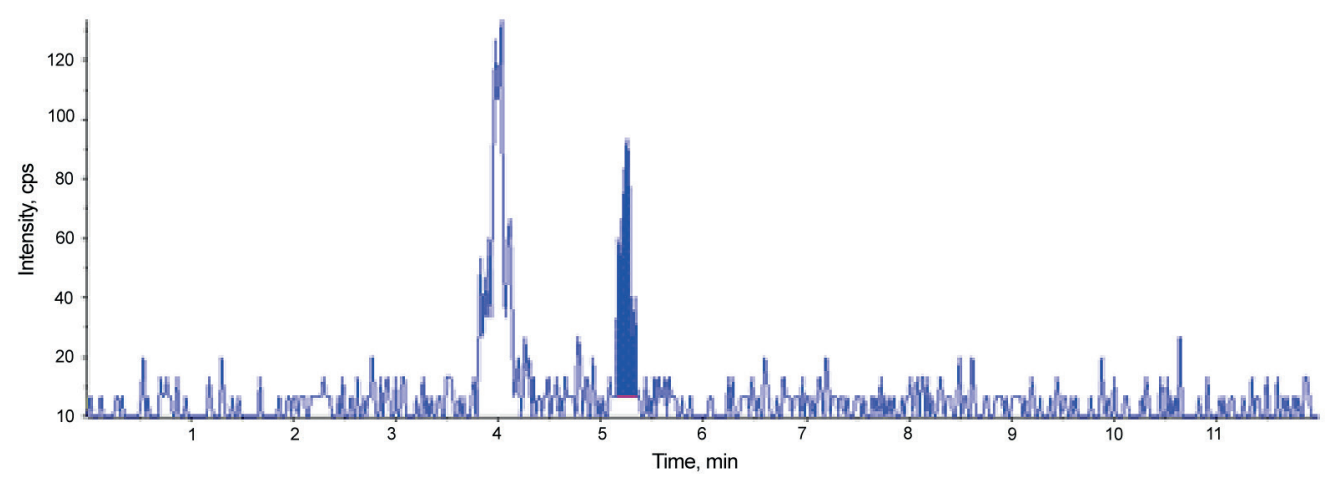

Figure 2

Chromatogram of extracted estrone in Sample D

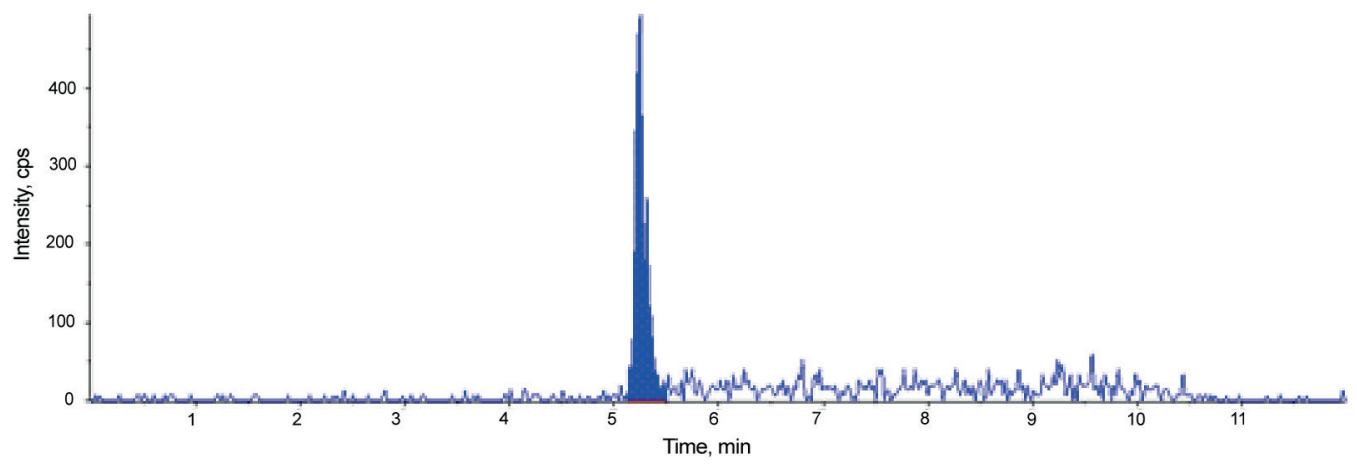

Figure 3

Chromatogram of extracted estrone in Sample E

\begin{tabular}{|l|c|c|c|c|c|c|c|}
\hline \multicolumn{7}{|c|}{ Comparison of detection of hormones in surface waters with other studies } \\
\hline Country & $\begin{array}{c}\text { a-E2 } \\
\left(\mathbf{n g} \cdot \mathbf{L}^{-1}\right)\end{array}$ & $\begin{array}{c}\beta-E 2 \\
\left(\mathbf{n g} \cdot \mathbf{L}^{-1}\right)\end{array}$ & $\begin{array}{c}\text { EE2 } \\
\left(\mathbf{n g} \cdot \mathbf{L}^{-1}\right)\end{array}$ & $\begin{array}{c}\text { E1 } \\
\left(\mathbf{n g} \cdot \mathbf{L}^{-1}\right)\end{array}$ & $\begin{array}{c}\text { Sample } \\
\text { pre-treatment }\end{array}$ & $\begin{array}{c}\text { Analytical } \\
\text { technique }\end{array}$ & Reference \\
\hline Netherlands & $0.3-3.0$ & $0.3-5.5$ & $0.1-4.3$ & $0.1-3.4$ & LC fractionation & GC-MS & (Belfroid et al., 1999) \\
\hline China & $0.0-1.8$ & - & $0.0-2.7$ & $0.5-3.1$ & Derivatisation & GC-MS & (Ahmed et al., 2017) \\
\hline Germany & - & - & - & $0.0-1.6$ & SPE/derivatisation & GC-MS & (Carballa et al., 2004) \\
\hline South Korea & - & - & - & $1.8-5.0$ & SPE & LC-MS & $($ Kim et al., 2007) \\
\hline South Africa & - & - & - & $0.9-4.4$ & SPE & LC-MS & This study \\
\hline
\end{tabular}

1 to $5 \mathrm{ng} \cdot \mathrm{L}^{-1}$ obtained in The Netherlands, with estrone being the most frequently observed oestrogen hormone (Belfroid et al., 1999). Ying et al. (2002) reported that oestrogens in humans and animals undergo various degradation mechanisms, taking place mainly in the liver; they are frequently oxidised, hydroxylated, deoxylated and methylated prior to the final conjugation with glucuronic acid or sulphate. In another study, Hohenblum et al. (2004) reported $17 \beta$-estradiol in the range of 0.1 to $0.8 \mathrm{ng} \cdot \mathrm{L}^{-1}$ in Austrian groundwater. Various oestrogenic compounds were detected in ground and surface waters of France within the range of 0.1 to $1 \mathrm{ng} \cdot \mathrm{L}^{-1}$, even though the fate and impact of these compounds on public health is not clearly known (Vulliet et al., 2011).

This study shows that no oestrogen hormone was detected in any of the 8 treated drinking water samples in the south of Johannesburg, during both seasons. These results were comparable to other researchers; Dévier et al. (2013) reported the absence of these four oestrogenic hormones in Evian and Volvic (bottled natural mineral waters). However, estriol has been detected at the drinking water treatment plant of Abrera in Spain at a concentration of $11.60 \mathrm{ng} \cdot \mathrm{L}^{-1}$ (Kuster et al., 2008).

E2 is rapidly oxidised to estrone, which can be further converted into estriol, the major excretion product which has not been determined in this study. A study performed on Canadian and German wastewater samples detected estrone at a maximum concentration level of $70 \mathrm{ng} \cdot \mathrm{L}^{-1}$. However, a concentration of $1.6 \mathrm{ng} \cdot \mathrm{L}^{-1}$ estrone was detected in surface and stream water samples. This can support the rapid degradation of estrone into estriol (Ying et al., 2002). 


\section{CONCLUSION AND RECOMMENDATIONS}

An analytical method has been developed and validated to identify and quantify 4 hormones in raw and treated drinking water samples with the accuracy ranging between 93.8 and $100.9 \%$ and the limit of quantification in the range of 0.24 to $0.32 \mathrm{ng} \cdot \mathrm{L}^{-1}$ for all analytes.

UFLC-MS is a suitable analytical technique for the determination of oestrogen hormones in water samples compared to the commonly used GC-MS which requires derivatisation. Derivatisation steps are not only time consuming and laborious but also tedious.

The high accuracy, good precision, adequate LODs and LOQs obtained by SPE and UFLC interfaced to a MS-MS demonstrates that the developed method is suitable for determination of oestrogen hormones in source and drinking water samples.

It is recommended that a method for wastewater analysis be developed and validated to detect these compounds in wastewater treatment plants in South Africa in order to confirm the source of their occurrence and identify technologies for their removal. The outcome of the study will foster collaboration among stakeholders to establish a list of important oestrogens to be monitored and to effect legislation in South Africa.

\section{ACKNOWLEDGMENTS}

Rand Water Analytical Services is acknowledged for providing the facilities and funding to make this project a success.

\section{REFERENCES}

AHMED MB, ZHOU JL, NGO HH, GUO W, THOMAIDIS NS and XU J (2017) Progress in the biological and chemical treatment technologies for emerging contaminant removal from wastewater: A critical review. J. Hazardous Mater. 323 274-298. https://doi. org/10.1016/j.jhazmat.2016.04.045

AMIN S, ZHANG Y, FELSON DT, SAWIN CT, HANNAN MT, WILSON PWF and KIEL DP (2006) Estradiol, testosterone, and the risk for hip fractures in elderly men from the Framingham Study. Am. J. Med. 119 (5) 426-433. https://doi.org/10.1016/j. amjmed.2005.10.048

ARIS AZ, SHAMSUDDIN AS, and PRAVEENA SM (2014) Occurrence of 17a-ethynylestradiol (EE2) in the environment and effect on exposed biota: a review. Environ. Int. 69 104-119. https:/doi. org/10.1016/j.envint.2014.04.011

BELFROID AC, VAN DER HORST A, VETHAAK AD, SCHÄFER AJ, RIJS GBJ, WEGENER J and COFINO WP (1999) Analysis and occurrence of estrogenic hormones and their glucuronides in surface water and waste water in The Netherlands. $S c i$. Total Environ. 225 (1-2) 101-108. https://doi.org/10.1016/ S0048-9697(98)00336-2

CARABIAS-MARTÍNEZ R, RODRÍGUEZ-GONZALO E and REVILLA-RUIZ P (2004) Determination of weakly acidic endocrine-disrupting compounds by liquid chromatographymass spectrometry with post-column base addition. $J$. Chromatogr. A 1056 (1-2) 131-138. https://doi.org/10.1016/j. chroma.2004.06.121

CARBALLA M, OMIL F, LEMA JM, LLOMPART MA, GARCÍAJARES C, RODRÍGUEZ I, and TERNES T (2004) Behavior of pharmaceuticals, cosmetics and hormones in a sewage treatment plant. Water Res. 38 (12) 2918-2926. https://doi.org/10.1016/j. watres.2004.03.029

CHAN ECY, PASIKANTI KK and NICHOLSON JK (2011) Global urinary metabolic profiling procedures using gas chromatographymass spectrometry. Nat. Protocols 6 (10) 1483-1499. https://doi. org/10.1038/nprot.2011.375
DE JAGER AD and BAILEY NL. (2011) Online extraction LC-MS/MS method for the simultaneous quantitative confirmation of urine drugs of abuse and metabolites: Amphetamines, opiates, cocaine, cannabis, benzodiazepines and methadone. J. Chromatogr. B 879 (25) 2642-2652. https://doi.org/10.1016/j.jchromb.2011.07.029

DÉVIER MH, LE MENACH K, VIGLINO L, DI GIOIA L, LACHASSAGNE P and BUDZINSKI H (2013) Ultra-trace analysis of hormones, pharmaceutical substances, alkylphenols and phthalates in two French natural mineral waters. Sci. Total Environ. 443 621-632. https://doi.org/10.1016/j.scitotenv.2012.10.015

GUSTAVO GONZÁLEZ A and ÁNGELES HERRADOR M (2007) A practical guide to analytical method validation, including measurement uncertainty and accuracy profiles. Trends Anal. Chem. 26 (3) 227-238. https://doi.org/10.1016/j.trac.2007.01.009

HOHENBLUM P, GANS O, MOCHE W, SCHARF S and LORBEER G (2004) Monitoring of selected estrogenic hormones and industrial chemicals in ground waters and surface waters in Austria. Sci. Total Environ. 333 (1-3) 185-193. https://doi.org/10.1016/j. scitotenv.2004.05.009

HUERTA-FONTELA M, GALCERAN MT and VENTURA F (2010) Fast liquid chromatography-quadrupole-linear ion trap mass spectrometry for the analysis of pharmaceuticals and hormones in water resources. J. Chromatogr. A 1217 (25) 4212-4222. https://doi. org/10.1016/j.chroma.2009.11.007

HUERTA-FONTELA M, GALCERAN MT and VENTURA F (2011) Occurrence and removal of pharmaceuticals and hormones through drinking water treatment. Water Res. 45 (3) 1432-1442. https://doi.org/10.1016/j.watres.2010.10.036

INGERSLEV F and HALLING-SØRENSEN B (2003) Evaluation of analytical chemical methods for detection of estrogens in the environment. Danish Environmental Protection Agency, Denmark. $69 \mathrm{pp}$.

IZUMI Y, OKAZAWA A, BAMBA T, KOBAYASHI A and FUKUSAKI E (2009) Development of a method for comprehensive and quantitative analysis of plant hormones by highly sensitive nanoflow liquid chromatography-electrospray ionization-ion trap mass spectrometry. Anal. Chim. Acta 648 (2) 215-225. https://doi. org/10.1016/j.aca.2009.07.001

KIM SD, CHO J, KIM IS, VANDERFORD BJ and SNYDER SA (2007) Occurrence and removal of pharmaceuticals and endocrine disruptors in South Korean surface, drinking, and waste waters. Water Res. 41 (5) 1013-1021. https://doi.org/10.1016/j. watres.2006.06.034

KOAL T, SCHMIEDERER D, PHAM-TUAN H, RÖHRING C and RAUH M (2012) Standardized LC-MS/MS based steroid hormone profile-analysis. J. Steroid Biochem. Molec. Biol. 129 (3) 129-138. https://doi.org/10.1016/j.jsbmb.2011.12.001

KUSTER M, LÓPEZ DE ALDA MJ, HERNANDO MD, PETROVIC M, MARTÍN-ALONSO J and BARCELÓ D (2008) Analysis and occurrence of pharmaceuticals, estrogens, progestogens and polar pesticides in sewage treatment plant effluents, river water and drinking water in the Llobregat river basin (Barcelona, Spain). J. Hydrol. 358 (1-2) 112-123. https://doi.org/10.1016/j. jhydrol.2008.05.030

LAFLEUR AD and SCHUG KA (2011) A review of separation methods for the determination of estrogens and plastics-derived estrogen mimics from aqueous systems. Anal. Chim. Acta 696 (1-2) 6-26. https://doi.org/10.1016/j.aca.2011.03.054

LEWIS KM and ARCHER RD (1979) pKa values of estrone, $17 \beta$-estradiol and 2-methoxyestrone. Steroids 34 (5) 485-499. https://doi.org/10.1016/S0039-128X(79)80011-2

MARTINI FH, NATH JL and BARTHOLOMEW EF (2015) Fundamentals of Anatomy and Physiology. Pentice Hall, New Jersey. $538 \mathrm{pp}$.

NGUYEN HP (2011) Estrogen analysis by liquid chromatography-mass spectrometry. PhD thesis, University of Texas at Arlington.

PAILLER JY, KREIN A, PFISTER L, HOFFMANN L and GUIGNARD C (2009) Solid phase extraction coupled to liquid chromatographytandem mass spectrometry analysis of sulfonamides, tetracyclines, analgesics and hormones in surface water and wastewater in Luxembourg. Sci. Total Environ. 407 (16) 4736-4743. https://doi. org/10.1016/j.scitotenv.2009.04.042

RAMSEY MH and ELLISON SL (2007) Eurachem/EUROLAB/CITAC/ 
Guide: Measurement uncertainty arising from sampling: a guide to methods and approaches. Accredit. Qual. Assur. 15 (9) 533-535.

RICHARDSON SD (2009) Water analysis: emerging contaminants and current issues. Anal. Chem. 81 (12) 4645-4677. https://doi. org/10.1021/ac9008012

TEDMON L, BARNES JS, NGUYEN HP and SCHUG KA (2013)

Differentiating isobaric steroid hormone metabolites using multistage tandem mass spectrometry. J. Am. Soc. Mass Spectrom. 24 (3) 399-409. https://doi.org/10.1007/s13361-012-0542-4

VOGESER M and SEGER C (2016) Quality management in clinical application of mass spectrometry measurement systems. Clin. Biochem. 49 (13-14) 947-954. https://doi.org/10.1016/j. clinbiochem.2016.07.005

VULLIET E and CREN-OLIVÉ C (2011) Screening of pharmaceuticals and hormones at the regional scale, in surface and groundwaters intended to human consumption. Environ. Pollut. 159 (10)
2929-2934. https://doi.org/10.1016/j.envpol.2011.04.033

ESWE Institute for Water Research and Water Technology (JOGU-ESWE) (2003) Final Report ENV.D.1/ETU/2000/0083. URL: https://www.researchgate.net/profile/Andrea_Wenzel/ publication/229005028_Study_on_endocrine_disrupters_in_ drinking_water/links/02e7e525d25243aef7000000.pdf (Accessed 19 August 2016).

WOLFF K, FARRELL M, MARSDEN J, MONTEIRO M, ALI

R, WELCH S and STRANG J (1999) A review of biological indicators of illicit drug use, practical considerations and clinical usefulness. Addiction 94 (9) 1279-1298. https://doi. org/10.1046/j.1360-0443.1999.94912792.x

YING GG, KOOKANA RS and RU YJ (2002) Occurrence and fate of hormone steroids in the environment. Environ. Int. 28 (6) 545-551. https://doi.org/10.1016/S0160-4120(02)00075-2 